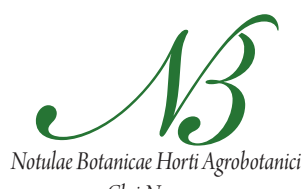

Cluj-Napoca

\title{
The Determination of the Iridoids from the Melampyrum species by Modern Chromatographic Methods
}

\author{
Melania F.MUNTEANU' ${ }^{1}$ Laurian VLASE² \\ "Vasile Goldiş” West University, Faculty of Pharmacy, Arad, Romania; anaionescuro@yahoo.com \\ ${ }^{2}$ "Iuliu Hateganu" University of Medicine and Pharmacy from Cluj-Napoca, Faculty of Pharmacy, Romania
}

\begin{abstract}
The idea of studying the iridoids from the Melampyrum bihariense Kern has started from the few data found about the chemical composition of this species. The literature mentions the presence of iridoids found in two species of Melampyrum: Melampyrum arvense and Melampyrum cristatum. The study consists of a qualitative and quantitative analysis by modern chromatographic methods, TLC. TLC coupled with photo-densitometry as well as chromatography on the high performance column (LC/MS). The methanol extract was done from the flowers and leaves of Melamphyrum bihariense. For the TLC and HPLC, the aucubin was used as standard solution. The obtained chromatogram was examined in visible light spectrum, and then it was revealed with sulphuric anisaldehyde, emphasizing the brown coloured spots. In the TLC case, the chromatographic plate was scanned with a Shimadzu CS9000 photo densitometer after spraying with iron chloride, and for the HPLC the analytical column Atlantis HILIC was used $100 \mathrm{~mm}$ x $3.0 \mathrm{~mm}, 3.5 \mu \mathrm{m}$ (water), and the ESI source of ions (electrospray ionisation). After the TLC analysis, the iridoids concentration found in the aucubin is $0.23 \mathrm{mg} / \mathrm{mL}$ in flowers and $0.24 \mathrm{mg} / \mathrm{mL}$ in leaves, and by the LC/MS method the concentration is of $1.8125 \mathrm{mg} / \mathrm{ml}$ in flowers and $2.3037 \mathrm{mg} / \mathrm{ml}$ in leaves.
\end{abstract}

Keywords: aucubin, HPLC-MS, iridoids, Melampyrum bihariense Kern., TLC

\section{Introduction}

Melampyrum bihariense Kern. belongs to Romania's spontaneous flora being framed, from the systematic point of view, in the Melampyrum species, the Scrophulariaceae family. Until now the Melampyrum genus, respectively the Melampyrum bihariense species was not studied in Romania, but the few data that were found show the existence of aucubin in other species of this genus. The Melampyrum name results from two Greek words: "melas"-black and "pyros"-wheat, the seeds of this plant having the grain wheat aspect, except for the fact that they are black coloured, which leads us to the possibility of iridoids existence in this species. The only reference found in the specialized international literature is the one that specifies the composition of the two species: Melampyrum arvense and Melampyrum cristatum, but this is far too little to be a term of comparison. The two species contain: aucubin, gardosid methyl ester. The iridoids represent a group of pentamethylene-pyrinic monoterpenes, but their presence in the plant was signalled ever since 1846 . The physiological role of these substances is little studied, but the bitter taste and the antibiotic properties of some of them leads to the hypothesis of a possible role in the protection of plants (Damtoft et al., 1984).

\section{Materials and methods}

\section{Experimental part}

The vegetal material was harvested from Mureş county, Ercea village (Romania) on the $24^{\text {th }}$ June 2004. The leaves and flowers of the Melampyrum bihariense species were used for analysis. The extraction method: the starting point is $10 \mathrm{~g}$ of vegetable product, which was extracted with 100 $\mathrm{ml}$ methyl alcohol and then the latter is completely evaporated (Munteanu et al., 2006).

TLC was performed under the following conditions: solution to analyze: methanol extract from the Melampyrum bihariense flowers (M2) and leaves (M1)-25 $\mu$ l applied; standard solution: aucubin methanol solution (Roth) $1.18 \mathrm{mg} / \mathrm{ml}-10 \mu \mathrm{l}$ applied; stationary phase: 60 F254 Kieselgel (Merck); mobile phase n-propanol (Merck)-toluene (Merck)-acetic acid (Merck)-water (25: 20:10:10, vol.); migration distance $10 \mathrm{~cm}$; migration time: $40 \mathrm{~min}$. The application of the solutions on the chromatographic plate was carried out in straps of $1 \mathrm{~cm}$ at $1.5 \mathrm{~cm}$ distance from the lower border of the plate. The chromatogram analysis is done in visible light spectrum. The development of the plate has been performed with sulphuric anisaldehyde $(0.5 \mathrm{ml}$ anisaldehyde $+5 \mathrm{ml}$ concentrated sulphuric acid $+10 \mathrm{ml}$ glacial acetic acid $+85 \mathrm{ml}$ metha- 
80

nol). After spraying, the plate was maintained 10 minutes at $105-110^{\circ} \mathrm{C}$ in stove and it was visualised 5 minutes after the cooling. In the case of iridoids, the reaction agent used for development gave the brown coloured spots. (Wagner and Blant, 1996). The second stage of analysis consists of TLC coupled with photo-densitometry. The thin layer chromatography has been accomplished by using the above mentioned experimental conditions. In TLC coupled with photo densitometry, the chromatographic plate was scanned with a Shimadzu CS9000 photo densitometer after spraying with iron chloride (anisaldehyde). The photo densitometer parameters: reflection mode, wolfram lamp, scanning method: zigzag, $\lambda=550 \mathrm{~nm}$ (Manguro $e t$ al., 2011).

The third method for the identification and the quantitative analysis of aucubin (Fig. 1) from the vegetal extracts uses the high performance liquid chromatography coupled with mass spectrometry (LC/MS).

The third method for the identification and quantitative analysis of the aucubin from vegetal extracts used the high performance liquid chromatography coupled with mass spectrometry (LC/MS).

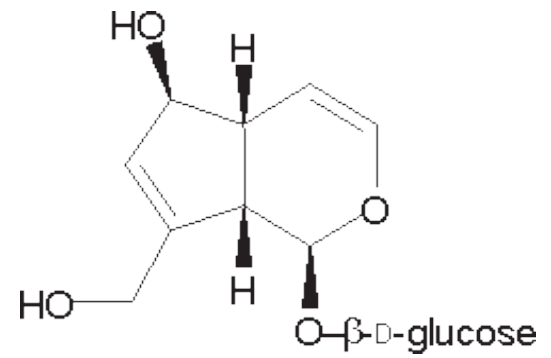

Fig. 1. Aucubin chemical formula

Standards: For the quantitative determination, the standard aucubin from Roth, Germany was used (Toiu et al., 2008).

The HPLC conditions coupled with mass spectrometry conditions: binary pump; auto-sampler; HP 1100 thermostat; HP 1100 Series UV detector; Agilent Ion Trap 1100 VL mass spectrometer. HPLC working condition: Atlantis HILIC analytical column $100 \mathrm{~mm} \times 3.0 \mathrm{~mm}$ id., 3.5 $\mu \mathrm{M}$ (Water); on-line filter of 0.2 microns (Agilent); mobile phase: mixture water-acetonitrile, the gradient elution after the following program: start $95 \%$ acetonitrile, at $2.30 \mathrm{~min}-81.1 \%$ acetonitrile, at $2.31 \mathrm{~min}-10 \%$ acetonitrile, at $2.70 \mathrm{~min}-10 \%$ acetonitrile, at $2.71 \mathrm{~min}-95 \%$ acetonitrile.

Flow rate: $1 \mathrm{ml}$ per minute, temperature of $40^{\circ} \mathrm{C}$, column plus $1 \%$ of acetic acid solution in water, also containing $20 \mu \mathrm{M}$ sodium acetate, flow rate of $0.7 \mathrm{ml}$ per minute.

Detection: UVs, $208 \mathrm{~nm}$ (only for the visualization of the chromatographic profile) and MS monitoring of the ion with $\mathrm{m} / \mathrm{z} 369$ corresponding to adduct formed by aucubin with sodium ion. The injection volume was of 2 $\mu \mathrm{l}$. MS working condition: ESI ion source (electrospray ionization); positive mode; nitrogen as nebulising gas, pressure of $60 \mathrm{psi}$; drying gas-nitrogen, flow rate 121 per minute, temperature $300^{\circ} \mathrm{C}$, capillary potential: $4000 \mathrm{~V}$; method of analysis-MS-SIM monitoring of $\mathrm{m} / \mathrm{z} 369$ ion (Gousiadou et al., 2007; Li et al., 2008).

\section{Results and discussion}

In Fig. 2 the obtained TLC chromatogram is shown. The Rf obtained are presented in Tab. 1. The spots appear in the visible brown-violet light. One can notice a separation of aucubin in all the studied samples; therefore it can be identified quantitatively and qualitatively. The separation of aucubin was done at Rf of 0.24 . Other separated compounds appear in the chromatogram as well, but it couldn't be determined whether they belong or not to the iridoids class.

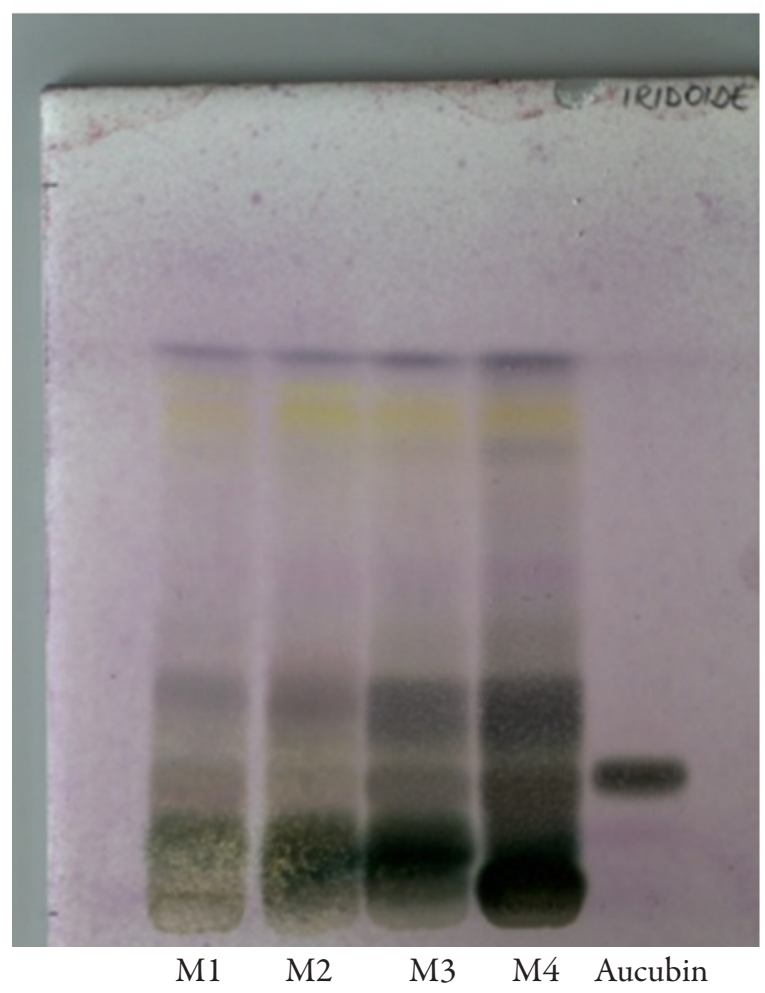

Fig. 2. The chromatogram of the Melampyrum extract and aucubin

Tab. 1. The Rf values

\begin{tabular}{cccc}
\hline Sample & $\mathrm{R}_{f}$ Value & Standard & $\mathrm{R}_{f}$ Value \\
\hline $\mathrm{M}_{1}$ & 0.23 & Aucubin & 0.24 \\
$\mathrm{M}_{2}$ & 0.24 & & \\
\hline
\end{tabular}

After the photodensitometric evaluation, some densitograms have been obtained, which show the presence of aucubin, in different concentrations.

After the photodensitometric evaluation, the aucubin test was performed. This test was performed through the 


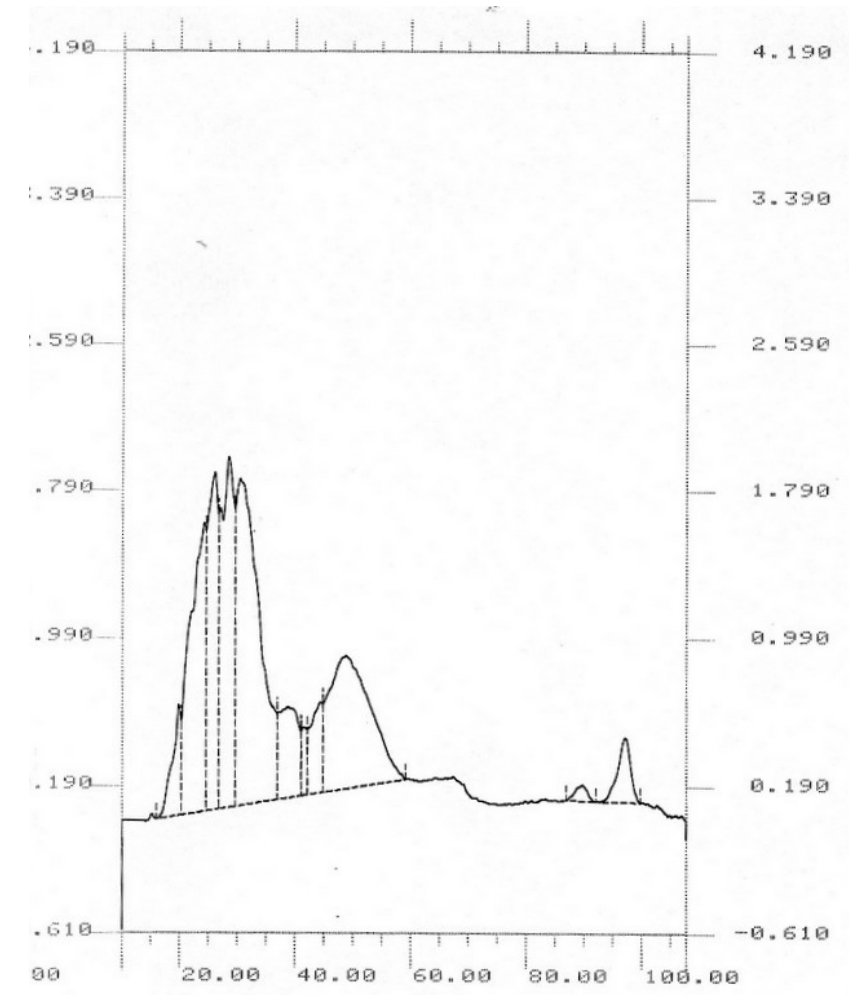

Fig. 3. The densitogram of the Melampyrum flowers extract (M2)

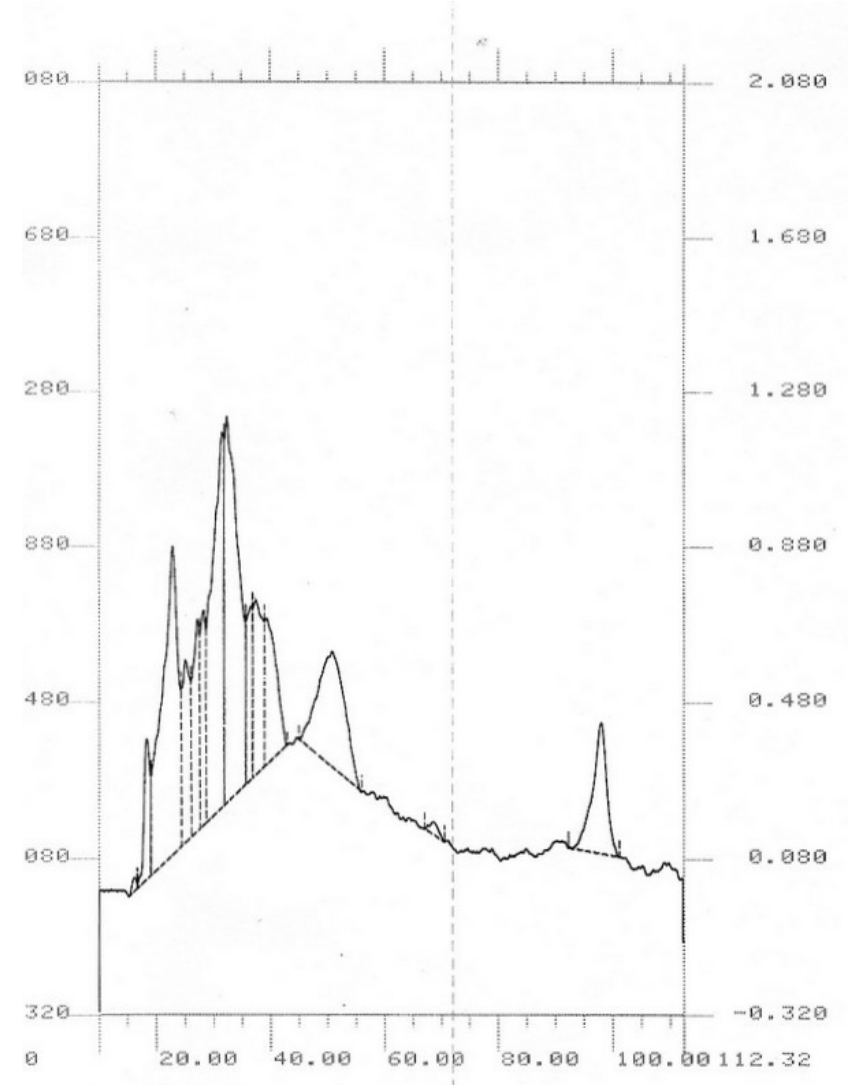

Fig. 4. The densitogram of the Melampyrum leaves extract (M1)

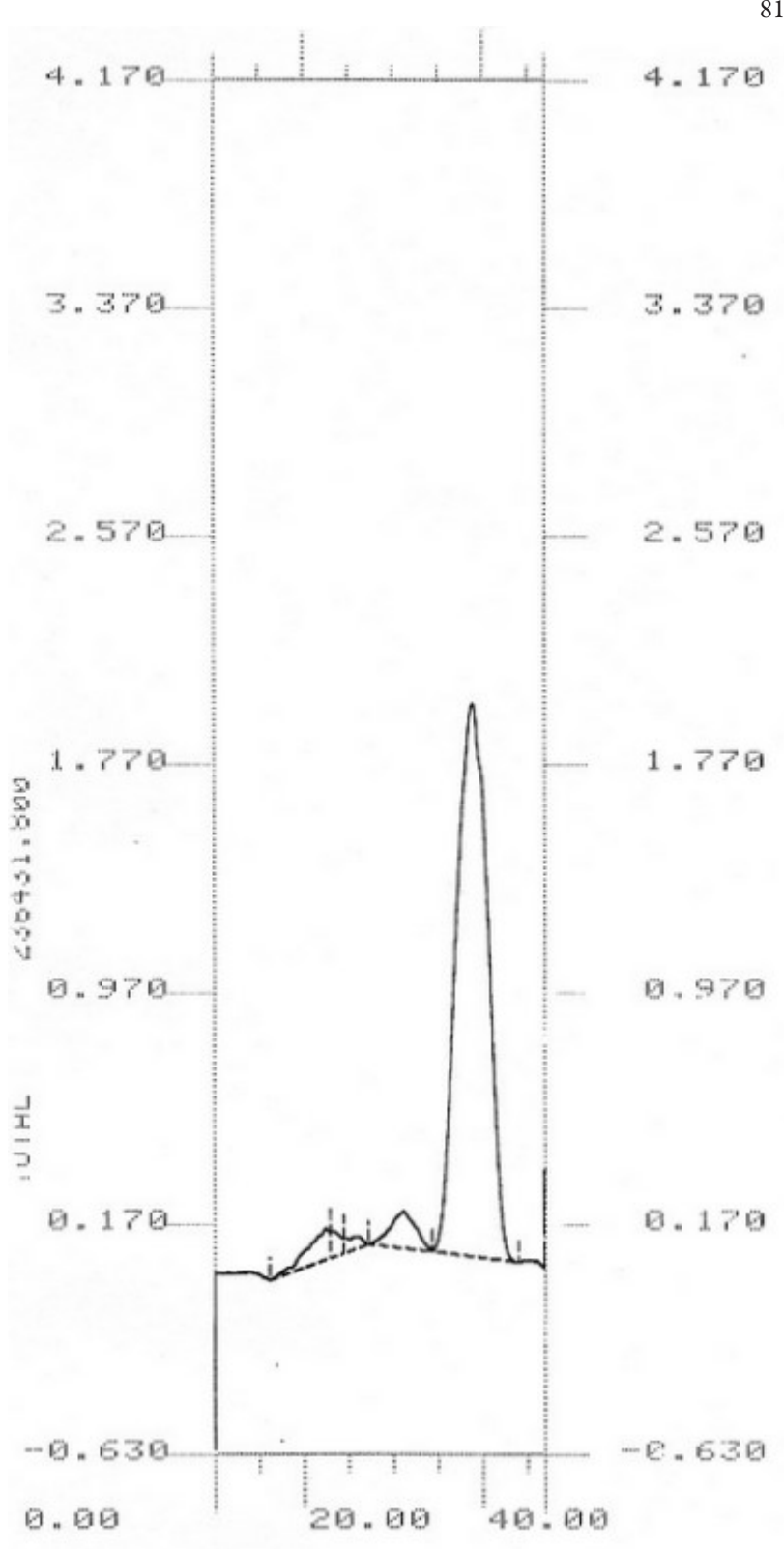

Fig. 5. The densitogram of standard aucubin

Tab. 2. The data for the calibration curve, expressed in aucubin

\begin{tabular}{cc}
\hline Concentration, $\mathrm{mg} / \mathrm{ml}$ & Area \\
\hline 0.1 & 42123.7 \\
0.2 & 75344.2 \\
0.3 & 122815 \\
0.4 & 160225.3 \\
0.5 & 194550.5 \\
\hline
\end{tabular}

calibration curve method, which was plated depending on the concentration area.

In Tab. 2 the data of the calibration curve in aucubin are shown, and in Fig. 6 the calibration curve is shown with the equation and the correlation ratio. The aucu- 
82

Tab. 3. The concentration of aucubin in the samples

\begin{tabular}{ccc}
\hline Sample & Area & Concentration, $\mathrm{mg} / \mathrm{ml}$ \\
$\mathrm{M}_{1}$ & 43272.6 & 0.11 \\
$\mathrm{M}_{2}$ & 47203.5 & 0.12 \\
\hline
\end{tabular}

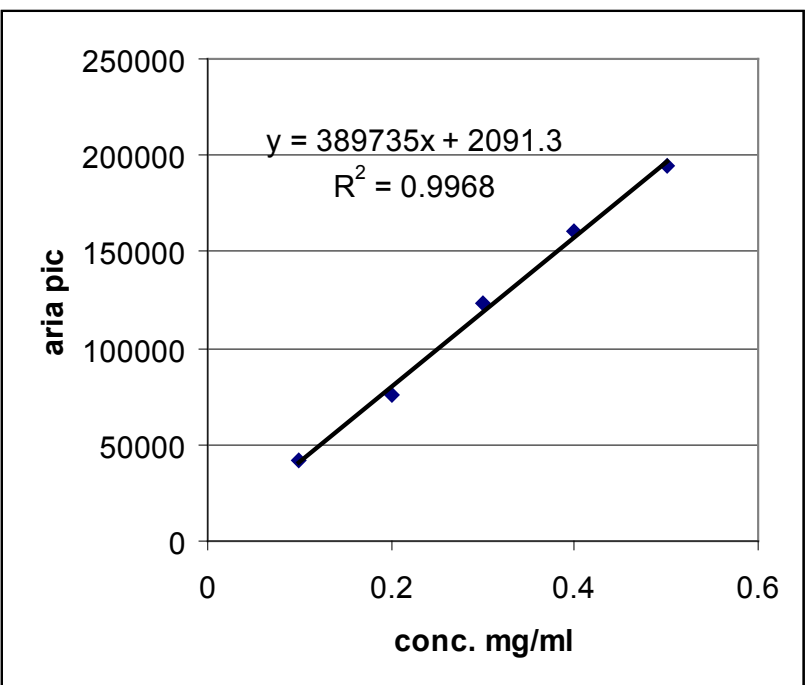

Fig. 6. The calibration curve expressed in aucubin

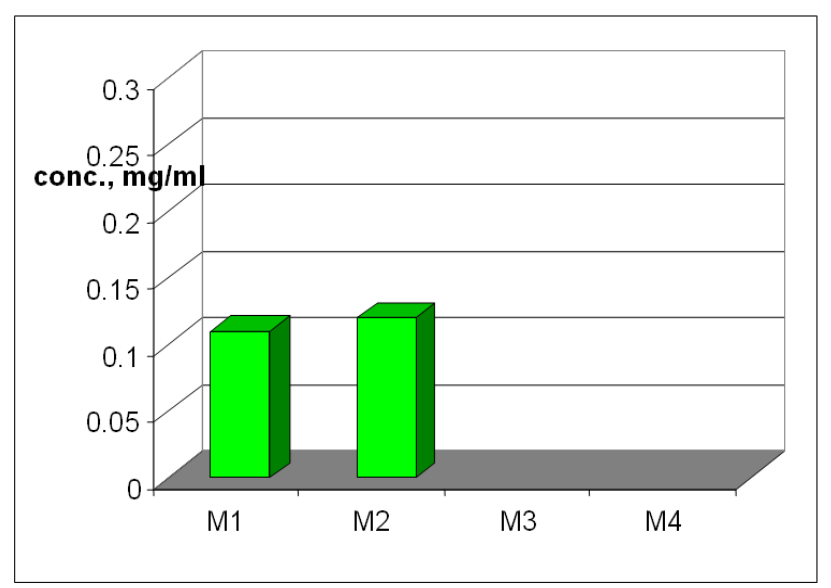

Fig. 7. The variation of aucubin concentration

bin concentrations were calculated in Tab. 2 based on the equation and data of the area presented for each test, shown in Tab. 3.

In Fig. 7 the histogram that indicates the variation of aucubin concentrations in the studied samples is shown.

The analysis was done for the mass spectrometry (MS), a phase of elimination of interferences was performed (a "cleaning" of the frequency spectrum). This phase leads to an analytical method whose sensitivity is doubled. Besides the MS signal, the absorbance in UV at $208 \mathrm{~nm}$ has also been monitored (corresponding to the maximum aucubin absorption) and it has been noticed that the MS detection is considerably more specific and sensitive than the UV detection in the case of aucubin.

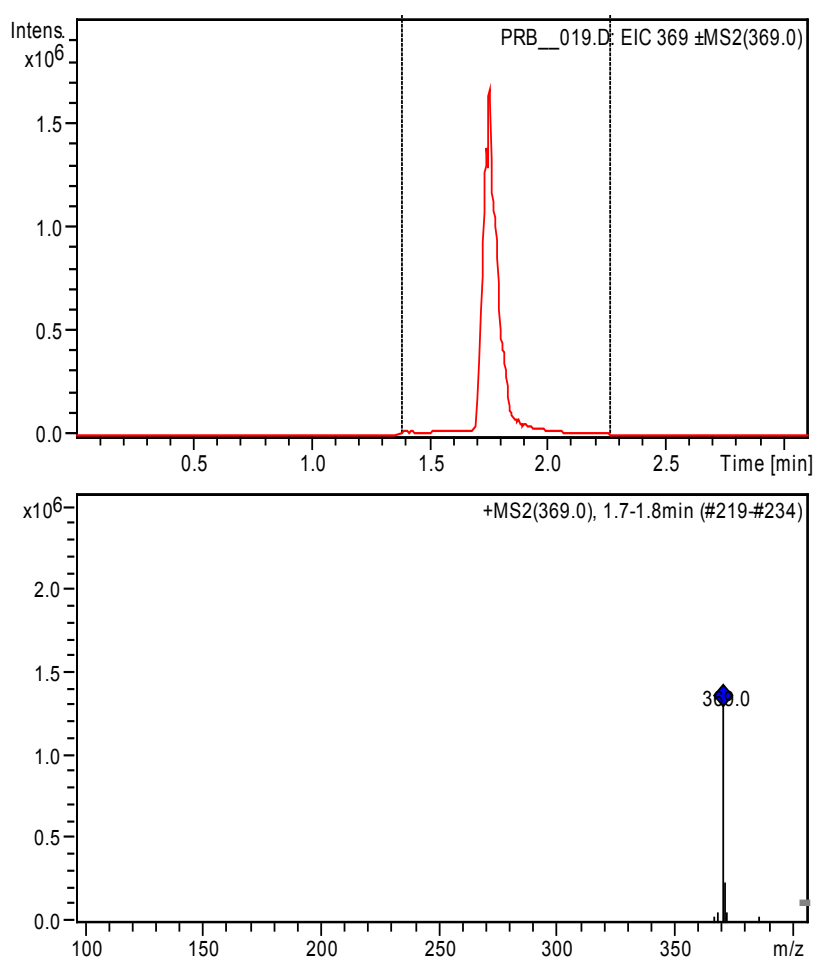

Fig. 8 . The chromatogram and the aucubin spectrum obtained by MS detection from the Melampyrum bihariense flowers sample

In Fig. 8 the chromatogram of the measure of the spectrum of Melampyrum bihariense flowers is shown, on which the quantification was done.

Tab. 4. Concentrations used for plating the calibration curve of the aucubin

\begin{tabular}{ccc}
\hline $\begin{array}{c}\text { The theoretical } \\
\text { concentration }(\mu \mathrm{g} / \mathrm{ml})\end{array}$ & $\begin{array}{c}\text { The measured } \\
\text { concentration }(\mu \mathrm{g} / \mathrm{ml})\end{array}$ & $\begin{array}{c}\text { Accuracy } \\
(\%)\end{array}$ \\
\hline 26.5 & 25.2 & -4.9 \\
79.5 & 88.2 & 10.9 \\
212.0 & 209.4 & -1.2 \\
318.0 & 325.4 & 2.3 \\
\hline
\end{tabular}

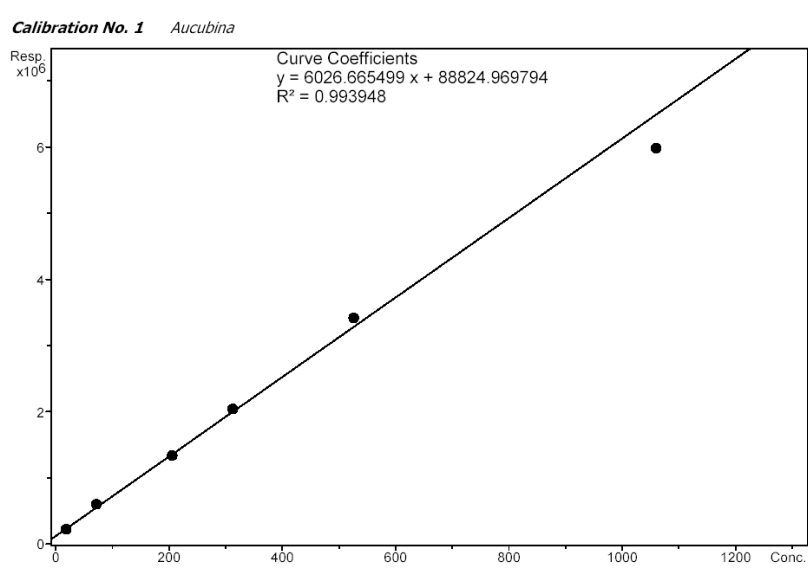

Fig. 9. The aucubin calibration curve, detection 
Tab. 5. Concentration of aucubin within the analyzed extracts

\begin{tabular}{cccc}
\hline Sample & $\begin{array}{c}\text { The obtained } \\
\text { concentration } \\
(\mu \mathrm{g} / \mathrm{ml})\end{array}$ & $\begin{array}{c}\text { Concentration } \\
\text { within the extract } \\
(\mu \mathrm{g} / \mathrm{ml})\end{array}$ & $\begin{array}{c}\text { Quantity } \\
\text { in } \mu \mathrm{g} / \mathrm{g} \\
\text { plant }\end{array}$ \\
\hline $\begin{array}{c}\mathrm{MB} \\
\text { leaves }\end{array}$ & 0.7678 & 230.37 & 767.8 \\
$\begin{array}{c}\mathrm{MB} \\
\text { fowers }\end{array}$ & 0.7136 & 142.72 & 142.72 \\
\hline
\end{tabular}

The calibration curve (Fig. 9) was performed in the range of concentration $26.5-1060 \mu \mathrm{g} / \mathrm{ml}$ (Tab. 4). All the solutions were prepared in acetonitrile.

\section{Conclusions}

Through the chromatographic analysis of the methanol extracts of the leaves and flowers of this species, the presence of aucubin was emphasized. The identification was performed through the evaluation of the $\mathrm{Rf}$ values of the spots by comparing these values with the aucubin Rf. TLC coupled with photodensitometry allowed for a quantitative determination of aucubin, the aucubin concentration being between 0.11 and $0.12 \mathrm{mg} / \mathrm{ml}$, and by TLC the concentration is $0.23 \mathrm{mg} / \mathrm{ml}$ in flowers and $0.24 \mathrm{mg} / \mathrm{ml}$ in leaves. The results show a higher concentration of aucubin in leaves than in flowers. The highest concentration of aucubin is found in the methanol extract of Melampyrum bihariense leaves. $(0.7678 \mu \mathrm{g} / \mathrm{ml})$.

Thus we can conclude that through the analysed methods, the leaves of this species have the highest concentration of aucubin.

\section{References}

Aberham A, Schwaiger S, Stuppner H, Ganzera M (2007). Quantitative analysis of iridoids, secoiridoids, xanthones and xanthone glycosides in Gentiana lutea L. roots by
RP-HPLC and LC-MS. Journal of Pharmaceutical and Biomedical Analysis 45:437-442.

Croci AN, Cioroiu B, Lazar D, Corciova A, Ivanescu B, Lazar MI (2009). HPLC evaluation of phenolic and polyphenolic acids from propolis. Farmacia LVII(1):52-57.

Damtoft S, Hansen BS, Jacobs B, Jensen RS, Nielsen JB (1984). Iridoid glucosides from Melampyrum. Phytochemistry 23(10):2387-2389.

Gousiadou C, Karioti A, Heilmann J, Skaltsa H (2007). Iridoids from Scutellaria albida ssp. albida. Phytochemistry 68:17991804.

Li Y, Yun W, Longxing W, Hongbin X, Zhengtao W, Zhibi H (2009). Rapid quantification of iridoid glycosides analogues in the formulated Chinese medicine Longdan Xiegan Decoction using high-performance liquid chromatography coupled with mass spectrometry. Journal of Chromatography A 1216:2098-2103.

Manguro OAL, Lemmen P, Hao P (2011). Iridoid Glycosides from Underground Parts of Ajuga remota, Academy of Chemistry of Globe Publications. Rec Nat Prod 5(3):147157.

Munteanu MF, Vlase L, Csedó C (2006). Determination of iridoide from Melampyrum cristatum species by chromatographyc methods. $4^{\text {th }}$ Conference on Medicinal and Aromatic Plants of South-East European Countries, $28^{\text {th }}-31^{\text {st }}$ of May, p. $454-456$.

Toiu A, Vlase L, Oniga I, Tamas M (2008). Quantitative analysis of some phenolic compounds from Viola species tinctures. Farmacia LVI(4):440-445.

Wagner H, Blant S (1996). Plant Drug Analysis. Springer Verlag, Berlin-Heidelberg. 